\title{
Time-related arterial changes after allogeneic hematopoietic stem cell transplantation in children
}

\author{
Maila I. Turanlahti' ${ }^{1}$, Mervi Taskinen² ${ }^{2}$ Ulla Saarinen-Pihkala ${ }^{2}$ and Eero V. Jokinen ${ }^{1}$
}

BACKGROUND: Metabolic syndrome is a frequent late effect in young adults after hematopoietic stem cell transplantation (HSCT) performed in childhood.

METHODS: To further study the signs of cardiovascular changes in HSCT patients, we performed noninvasive vascular ultrasonic measurements of arterial stiffness and endothelial function in 25 children (median age: $11.2 \mathrm{y}$ ) and in 22 healthy matched controls.

RESULTS: The distensibility of the common carotid artery (CCA) was significantly lower in the patients than in the controls (mean $=0.48, \mathrm{SD}=0.19$ vs. mean $=0.64 \mathrm{~mm} \mathrm{Hg}^{-1} \times$ $\left.10^{-2}, \mathrm{SD}=0.28 ; P=0.024\right)$. The distensibility decreased with time passed after HSCT $(P=0.009)$. The compliance of the CCA was decreased (mean $=0.10, S D=0.04$ vs. mean $=0.13 \mathrm{~mm}^{2}$ $\times \mathrm{mm} \mathrm{Hg}^{-1}, \mathrm{SD}=0.05 ; P=0.041$ ), and the incremental elastic modulus ( $E$ inc) was higher in the patients than in the controls $\left(\right.$ mean $=2.05, \mathrm{SD}=0.7 \mathrm{vs}$. mean $=1.6 \mathrm{~mm} \times 10^{3}, \mathrm{SD}=0.6$; $P=0.019)$. E inc was associated with time passed after HSCT $(P=0.036)$. The size of the brachial artery and flow-mediated dilation did not differ between the groups.

CONCLUSION: Early mechanical changes of the arterial wall were found at young age after HSCT. Ultrasonography may offer a noninvasive method to find early alterations of the vascular bed and to optimize prevention of atherosclerosis in HSCT patients.

$\mathbf{T}$ he number of long-term survivors after hematopoietic stem cell transplantation (HSCT) has increased, and, consequently, secondary morbidity and quality-of-life issues have become more and more important, especially in subjects who undergo transplantation in childhood $(1,2)$. Endocrinopathies, including growth hormone deficiency, hypothyroidism, and hypogonadism, are the most common late effects after HSCT $(1,3)$. However, metabolic (4) and cardiovascular morbidity (5), as newer entities in the field, may deserve more emphasis with elapsing time after transplantation. We observed insulin resistance, impaired glucose tolerance, and dyslipidemia in a time-correlated manner in one-third of the young adults studied 3-18 y after HSCT in childhood (4). Metabolic abnormalities have also been reported in adult female recipients of stem cell transplantation (6). Metabolic disturbances can be seen as a prologue to atherosclerosis, and even more cardiovascular morbidity may be anticipated in the middle-aged survivors of childhood malignancies.

Ultrasonography, as a noninvasive method, has been a valuable tool in revealing early changes in the endothelial function even in young children beyond 6 y with known underlying cardiovascular risk factors. In familial hypercholesterolemia, endothelial function is disturbed, and the carotid wall is stiffer from early childhood as compared with healthy controls (7-10). In children with low birth weight, endothelial dysfunction and altered stiffness of the common carotid artery (CCA) are found as young as the age of $9 \mathrm{y}$ $(9,10)$. In addition, chronic hyperglycemia impairs endothelial function (11), and the intima-media layer is thicker in diabetic children than in healthy age-matched controls (12). Both reduced flow-mediated vasodilation and increased intima-media thickness (IMT) have been proven to correlate with late atherosclerosis and cardiovascular morbidity and mortality in adults $(13,14)$.

The aim of this study was to evaluate whether HSCT performed in childhood, in addition to metabolic abnormalities, also implies early changes of arterial wall and endothelial function.

\section{RESULTS}

The anthropometric, hemodynamic, and biologic characteristics of the patients and controls are shown in Table 1. No differences in age or sex were found between the two groups, but the patients were shorter $(P=0.005)$ and weighed less $(P=0.04)$ than the age-matched controls. The patients with hormone deficiency were on appropriate substitution.

\section{Intima-Media Thickness}

The diameter or the IMT of the CCA did not differ between patients and controls (Table 2). However, intima-media was thicker in the male than in the female patients (mean $=0.50$, $\mathrm{SD}=0.058$ vs. mean $=0.43, \mathrm{SD}=0.049 ; P=0.003)$. In the controls, there was no significant difference between the males and the females. 
Table 1. Anthropometric, hemodynamic, and biological characteristics of the HSCT patients and the controls

\begin{tabular}{|c|c|c|c|}
\hline & Study patients & Controls & $P$ value \\
\hline$n(\mathrm{~F} / \mathrm{M})$ & $25(12 / 13)$ & $22(12 / 10)$ & \\
\hline Age, y (range) & $11.0(6.4-14.9)$ & $11.3(6.7-15.5)$ & 0.621 \\
\hline Weight, kg (range) & $35.4(18.5-70.0)^{*}$ & $43.1(22.3-71.8)$ & 0.040 \\
\hline Height, cm (range) & $139(116-163)^{*}$ & $152(117-183)$ & 0.005 \\
\hline $\mathrm{BMI}, \mathrm{kg} / \mathrm{m}^{2}$ (range) & $17.8(12.6-27.6)$ & $18.3(15.0-23.1)$ & 0.559 \\
\hline $\mathrm{SBP}, \mathrm{mm} \mathrm{Hg}, \mathrm{SD}$ & $106 \pm 11$ & $107 \pm 9$ & 0.844 \\
\hline $\mathrm{PP}, \mathrm{mm} \mathrm{Hg}, \mathrm{SD}$ & $49 \pm 8$ & $50 \pm 8$ & 0.651 \\
\hline $\mathrm{EF}, \%$ & $71.9 \pm 5.4$ & $71.6 \pm 6.9$ & 0.893 \\
\hline Total cholesterol, $\mathrm{mmol} / \mathrm{l}$ & $4.5 \pm 0.8$ & $4.4 \pm 0.7$ & 0.779 \\
\hline HDL cholesterol, mmol/l & $1.6 \pm 0.4$ & $1.7 \pm 0.3$ & 0.573 \\
\hline HDL/total cholesterol & $0.37 \pm 0.08$ & $0.40 \pm 0.07$ & 0.422 \\
\hline LDL cholesterol, mmol// & $2.3 \pm 0.7$ & $2.3 \pm 0.6$ & 0.92 \\
\hline Triglycerides, mmol/l & $1.1 \pm 0.7^{*}$ & $0.7 \pm 0.3$ & 0.026 \\
\hline fB-Gluc, mmol/l & $4.9 \pm 0.5$ & $4.8 \pm 0.4$ & 0.765 \\
\hline fB-insulin, $\mathrm{mmol} / \mathrm{l}$ & $14.2 \pm 30.3$ & $5.8 \pm 3.8$ & 0.224 \\
\hline
\end{tabular}

EF, ejection fraction; F, female; fB-Gluc, blood glucose after an overnight fast; fB-insulin, blood insulin after an overnight fast; HDL, high-density lipoprotein; HSCT, hematopoietic stem cell transplantation; LDL, low-density lipoprotein; M, male; PP, pulse pressure; SBP, systolic blood pressure.

${ }^{*} P<0.05$.

Table 2. Dimensions, mechanical properties of the CCA, and flowmediated brachial dilation in HSCT patients and controls (mean \pm SD)

\begin{tabular}{lccc}
\hline & Study patients & Controls & $P$ value \\
\hline $\mathrm{ESD}, \mathrm{mm}$ & $5.68 \pm 0.57$ & $5.81 \pm 0.38$ & 0.253 \\
$\mathrm{EDD}, \mathrm{mm}$ & $5.09 \pm 0.49$ & $5.04 \pm 0.32$ & 0.843 \\
$\Delta \mathrm{D}, \mathrm{mm}$ & $0.59 \pm 0.19^{*}$ & $0.77 \pm 0.24$ & 0.004 \\
$\Delta \mathrm{D} / \mathrm{EDD}, \%$ & $11.7 \pm 3.7^{*}$ & $15.4 \pm 5.3$ & 0.004 \\
$\mathrm{IMT}, \mathrm{mm}$ & $0.47 \pm 0.06$ & $0.47 \pm 0.05$ & 0.845 \\
$\mathrm{CCA}$ distensibility, $\mathrm{mm} \mathrm{Hg}^{-1} 10^{-2}$ & $0.48 \pm 0.19^{*}$ & $0.64 \pm 0.28$ & 0.024 \\
$\mathrm{CCA}$ compliance, $\mathrm{mm}^{2} \times \mathrm{mm} \mathrm{Hg}^{-1}$ & $0.10 \pm 0.04^{*}$ & $0,13 \pm 0.05$ & 0.041 \\
E inc, mm Hg $\times 10^{3}$ & $2.05 \pm 0.7^{*}$ & $1.6 \pm 0.6$ & 0.019 \\
Flow-mediated dilation, \% & $6.5 \pm 5.6$ & $6.3 \pm 4.2$ & 0.866 \\
\hline
\end{tabular}

CCA, common carotid artery; EDD, end-diastolic diameter; E inc, incremental elastic modulus; ESD, end-systolic diameter; HSCT, hematopoietic stem cell transplantation; IMT, intima-media thickness; $\triangle \mathrm{D}=\mathrm{ESD}-\mathrm{EDD}$.

${ }^{*} P<0.05$.

\section{Mechanical Properties of the CCA}

The distensibility of the CCA was significantly lower in patients than in controls (mean $=0.48, \mathrm{SD}=0.19$ vs. mean $\left.=0.64 \mathrm{~mm} \mathrm{Hg}^{-1} \times 10^{-2}, \mathrm{SD}=0.28 ; P=0.024\right)$ (Figure 1) and decreased with the time passed after HSCT $(P=0.009)$ (Figure 2). Distensibility was dependent on age only in the control group $(P=0.034)$. Compliance was also decreased in patients as compared with controls (mean $=0.10, \mathrm{SD}=$ 0.04 vs. mean $\left.=0.13 \mathrm{~mm}^{2} \times \mathrm{mm} \mathrm{Hg}^{-1}, \mathrm{SD}=0.05 ; P=0.041\right)$. Incremental elastic modulus ( $\mathrm{E}$ inc) was higher in HSCT patients than in controls (mean $=2.05, \mathrm{SD}=0.7$ vs. mean $=1.6 \mathrm{~mm} \times 10^{3}, \mathrm{SD}=0.6 ; P=0.019$ ) (Figure 3 ) and was

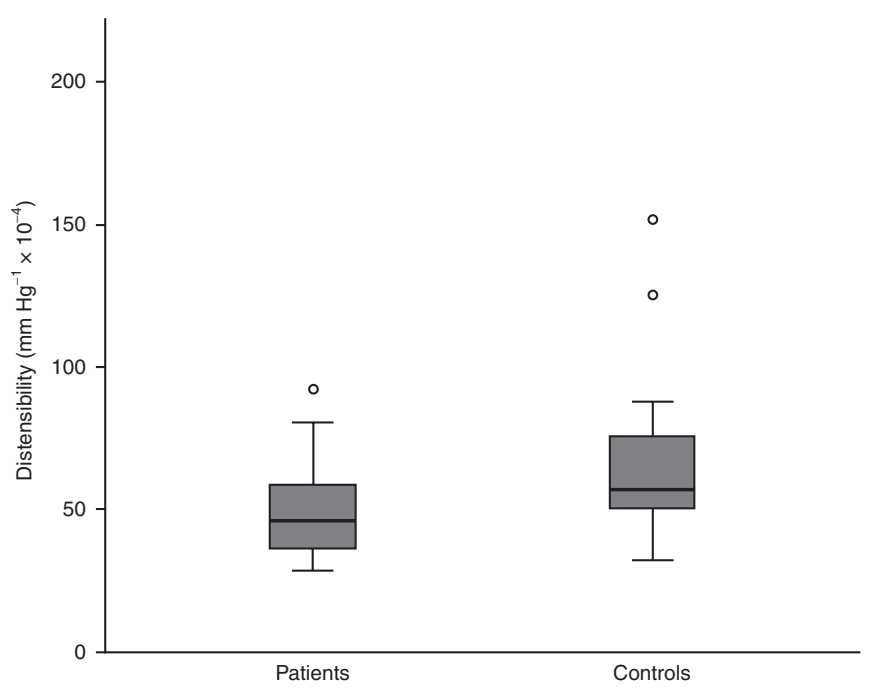

Figure 1. Distensibility in patients and controls. Circles are outliers (one in patient group and two in control group; difference to mean more than $2 \mathrm{SDs})$.

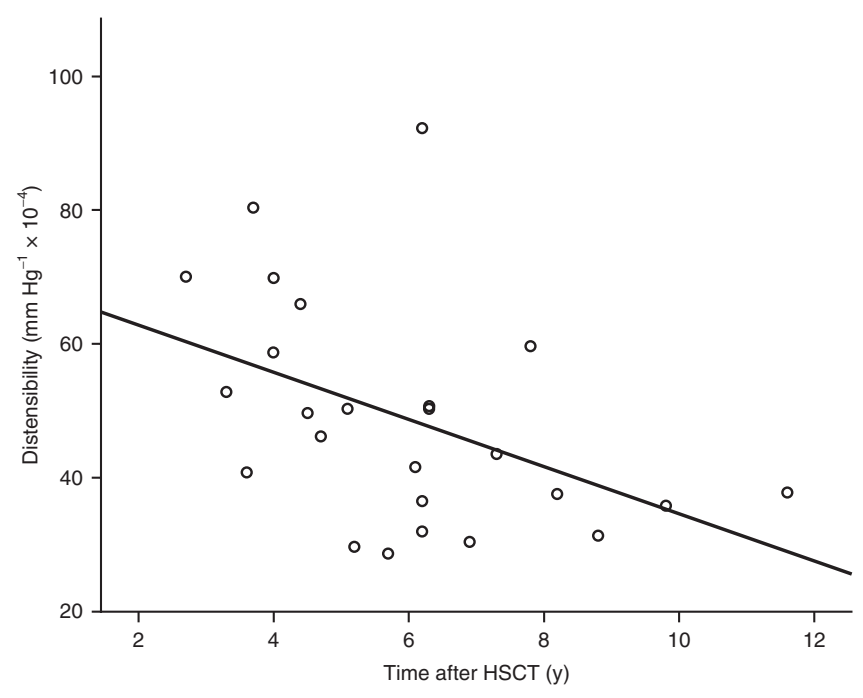

Figure 2. Distensibility in patients (circles) is associated with the time since HSCT. HSCT, hematopoietic stem cell transplantation.

dependent on the time since HSCT $(P=0.036)$ (Figure 4). No correlation was observed between age and $\mathrm{E}$ inc.

\section{Flow-Mediated Dilation}

There was no difference in the size of the brachial artery (mean $=3.04 \mathrm{~mm}, \mathrm{SD}=0.47$ vs. mean $=3.06, \mathrm{SD}=0.41$ ) or in the flow-mediated dilation (FMD) between the two groups.

\section{Patient Characteristics and Arterial Wall Changes}

Flow-mediated vasodilation tended to be slightly inferior in the 10 of 25 patients with hypothyroidism, although these patients were on appropriate hormone substitution (mean $=4.1 \%, \mathrm{SD}=3$ vs. mean $=8.2 \%, \mathrm{SD}=5.9 ; P=0.06)$. There was a negative correlation between total body irradiation $(0-14$ Gy) and distensibility of the CCA $(P=0.048)$, and also between total body irradiation and plasma high-density 


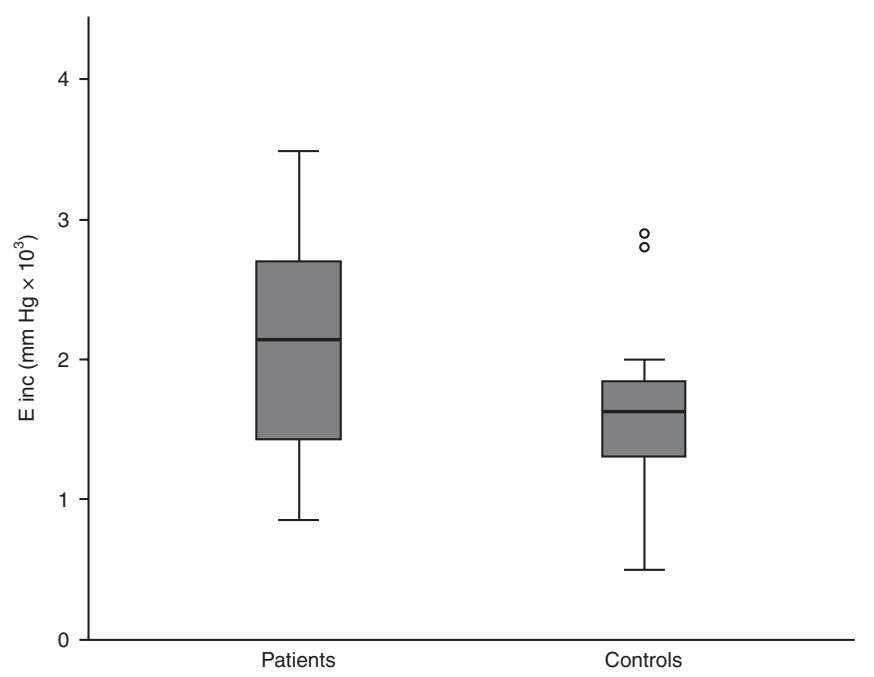

Figure 3. Incremental elastic modulus in patients and controls. In the control group, there were two outliers (circles; difference to mean more than 2 SDs).

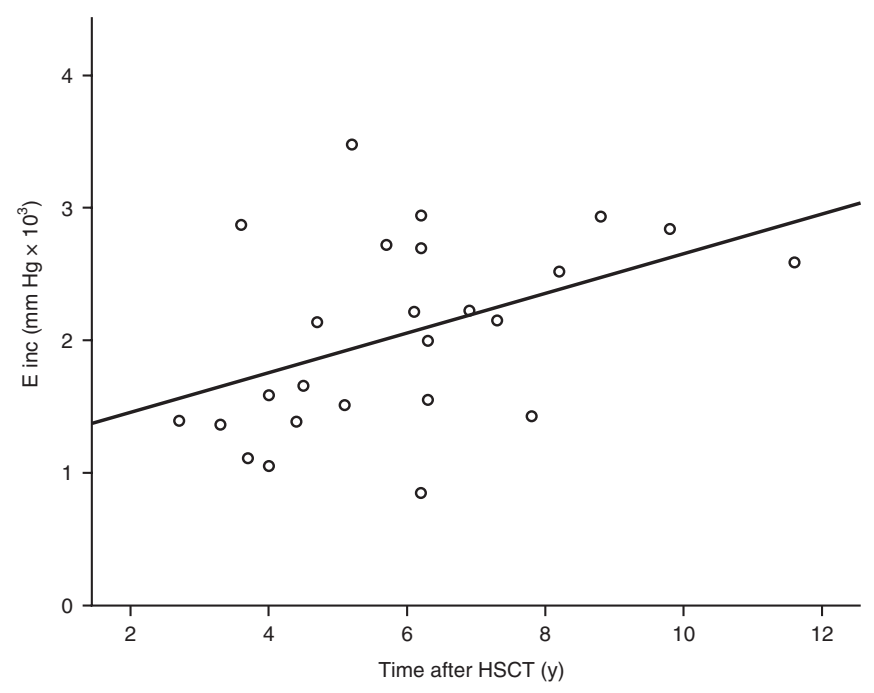

Figure 4. Incremental elastic modulus in patients (circles) is associated with the time after HSCT. HSCT, hematopoietic stem cell transplantation.

lipoprotein values $(P=0.004)$. Growth hormone deficiency, hypogonadism, microangiopathy, or clinical severity of acute or chronic graft-vs.-host disease (GVHD) did not correlate with IMT of the CCA or the elastic properties of the arterial wall.

Plasma triglyceride level, although within normal range, was higher in patients as compared with controls $(P=0.026)$ (Table 1). The mean plasma levels of total cholesterol, lowdensity lipoprotein cholesterol, high-density lipoprotein cholesterol, fasting glucose, and serum insulin did not differ between the two groups (Table 1). Plasma high-density lipoprotein cholesterol and the triglycerides correlated with distensibility of the CCA. In the patient group but not in the control group, triglyceride levels correlated with IMT. There was no correlation between insulin or glucose levels or the homeostasis model assessment index and CCA distensibility.

\section{DISCUSSION}

Our main observation is that the distensibility and the compliance of the CCA were significantly inferior in children and adolescents after HSCT as compared with healthy controls. These findings, together with higher values of $\mathrm{E}$ inc, indicate increased stiffness of the arterial wall. To our knowledge, this is a novel observation. Consequently, HSCT with adjuvant treatment may turn out to be an atherogenic stimulus to children and adolescents later in life.

Healthy endothelium is not only a passive lining of the blood vessels but also an active metabolic organ. Endothelium is a highly selective barrier for macromolecules as well as a surface maintaining the fluidity of blood (15). The endothelial cells control the tone of the vascular smooth muscle, control the activity of the coagulation status, and act in the immune response through an interaction with circulating leukocytes. Disturbances in arterial mechanical properties have been shown to relate to endothelial dysfunction and risk of cardiovascular events (16), and in our HSCT study population, these disturbances were observed at a very young age. Our findings also suggest that the changes in the arterial wall may increase with time passed since HSCT. Further studies are needed to evaluate whether these alterations in arterial stiffness are an end result of a transplant-related toxic insult or a cross-sectional image of an ongoing progressive process in the endothelial cells or in the arterial wall.

As a whole, HSCT affects the vascular endothelium. The endothelial disorders associated with HSCT can be divided into acute and chronic ones (15). The clinical manifestations of the acute endothelial damage are thrombotic microangiopathy, veno-occlusive disease, and capillary leak syndrome. Chronic GVHD is considered to be associated with chronic endothelial damage (15). Treatment-related toxic effects frequently trigger early vascular damage. Total body irradiation and chemotherapy, given either earlier before transplant or as part of the conditioning regimen, are associated with increased number of circulating endothelial cells as a marker of endothelial damage (17). A negative correlation between total body irradiation and arterial wall distensibility was also observed in our study; this suggests a toxic effect of total body irradiation on arterial wall. In addition, GVHD (18) and calcineurin inhibitors used in the prophylaxis of GVHD (19) may contribute to endothelial damage. In our study, neither acute-phase microangiopathy nor chronic GVHD were associated with changes in vascular endothelial function during the follow-up period. However, the number of patients in these subgroups was too small to allow statistically relevant considerations.

We did not observe any difference in FMD, an early marker of atherosclerosis, in our study cohort. By contrast, Chow et al. (20) found in a pilot study a significant decrease in flowmediated vasodilation in 14 young cancer patients treated with anthracyclines ( $300 \mathrm{mg} / \mathrm{m}^{2}$ or more). Dengel (21) showed decreased FMD response in young adults treated for acute lymphoblastic leukemia during childhood with chemotherapy with or without cranial radiation. In both of these studies, the patients were older than our patients, all of whom were younger 


\section{Articles | Turanlahti et al.}

Table 3. Transplant-related characteristics of the patient population

\begin{tabular}{|c|c|}
\hline & HSCT patients \\
\hline \multicolumn{2}{|l|}{ Diagnosis } \\
\hline ALL & 10 \\
\hline AML, MDS, CML & 8 \\
\hline Nonmalignant hematopoietic disease & 4 \\
\hline Other $^{\mathrm{a}}$ & 3 \\
\hline Age at HSCT, y (range) & $5.2(1.1-10.3)$ \\
\hline \multicolumn{2}{|l|}{ Conditioning } \\
\hline Cyclophosphamide & 11 \\
\hline Cytarabine & 13 \\
\hline Other $^{\mathrm{a}}$ & 1 \\
\hline TBI & 20 \\
\hline $10 \mathrm{~Gy}$ & 13 \\
\hline $12-14 \mathrm{~Gy}^{\mathrm{b}}$ & 7 \\
\hline \multicolumn{2}{|l|}{ Donor } \\
\hline HLA-identical sibling & 13 \\
\hline HLA-matched registry donor & 12 \\
\hline TMA & 3 \\
\hline \multicolumn{2}{|l|}{ Graft } \\
\hline Bone marrow & 22 \\
\hline Umbilical cord blood & 3 \\
\hline \multicolumn{2}{|l|}{ GVHD } \\
\hline Acute, grade $2-4^{c}$ & 7 \\
\hline Chronic & 11 \\
\hline Limited & 5 \\
\hline Extensive & 6 \\
\hline \multicolumn{2}{|l|}{ Late effects ${ }^{d}$} \\
\hline Hypothyroidism & 10 \\
\hline Growth hormone insufficiency & 6 \\
\hline Hypogonadism & 4 \\
\hline
\end{tabular}

ALL, acute lymphoblastic leukemia; AML, acute myeloid leukemia; CML, chronic myeloid leukemia; GVHD, graft-vs.-host disease; HLA, human leukocyte antigen; HSCT, hematopoietic stem cell transplantation; MDS, myelodysplastic syndrome; TBl, total body irradiation; TMA, thrombotic microangiopathy

aFamilial hemophagocytic histiocytosis, non-Hodgkin lymphoma, Chediak-Higashi syndrome, one of each. b ${ }^{b}$ Dose of TBI. 'Grade of acute graft-vs.-host reaction from mild (2/4) to severe (4/4). dThe patients with hormone deficiency were on appropriate substitution.

than $16 \mathrm{y}$. As changes in the CCA seemed to advance with time since HSCT, it may be that our patients were too young to show any changes in the brachial artery. In addition, the timing of the measurement after cuff deflation may explain our negative result. Järvisalo et al. (22) has found a great variation in the FMD as a function of the time after cuff deflation in healthy children. We chose to delay the measurement until 80-90 s after deflation to identify the late responders also, but the relatively large SD of the FMD may result from the variance in the response time in our patients. Continuous registration of the vessel diameter from 30 to $150 \mathrm{~s}$ is recommended to overcome the problem of the individual variation in FMD (22).
In 1992, Celermayer et al. (14) had already described a noninvasive method for testing endothelium-dependent vasodilation with high-resolution ultrasound. Nowadays, echographic methods are commonly used to assess not only the flow-mediated vasodilation of the brachial artery but also vascular changes in the wall of the carotid artery $(12,23)$. However, the ultrasonic method for the evaluation of the endothelial function is not yet clinical routine. As a noninvasive method, ultrasound is applicable, practical, and informative in a pediatric population (beyond the age of $6 y$ ), provided that the cooperation of the patient is good.

The core signs of metabolic syndrome-hypertriglyceridemia, hyperinsulinemia, and abdominal obesity - have been observed in one-third of the young long-term survivors after allogeneic HSCT $(4,24)$. Metabolic syndrome characterizes, at least when left untreated, a process from single disturbances in lipid and glucose metabolism to hypertension, type 2 diabetes, and severe cardiovascular disease (25). In our study, young HSCT patients had a higher mean levels of plasma triglycerides than controls, and in a former study, we showed that the metabolic disturbances may proceed over the time after HSCT (4).

The arterial wall changes, together with metabolic abnormalities, may contribute to the premature development of cardiovascular disease. It could be useful to perform vascular ultrasound for these patients in adolescence and repeat it after $5 \mathrm{y}$, and at the same time to evaluate lipid and glucose metabolism. We also recommend that these young patients avoid lifestyle risk factors such as smoking and overweight.

Heterogeneity of the diagnoses reflects the clinical reality, but it is also a source of bias in our study. In addition, a larger number of patients with nonmalignant diseases would have given the tools to compare the impact of pretransplant and conditioning chemotherapy on the vascular wall changes. All the ultrasonographic measurements were performed by the same experienced examiner, which we consider a strength of our study.

In conclusion, early alterations of the arterial wall were found after HSCT. Time after HSCT and total body irradiation seemed to affect arterial stiffness. The evaluation of early vascular changes in childhood offers the option of preventive treatment and counseling to avoid secondary morbidity, especially premature atherosclerosis.

\section{METHODS}

\section{Subjects}

This study was performed at the Children's Hospital, Helsinki University Central Hospital and University of Helsinki, Finland, in 2003-2006. The study population consisted of 25 children who had undergone allogeneic HSCT and 22 age- and gender-matched controls. All subjects were recruited after informed written consent from the parent(s) and from the age-appropriate children. The study was conducted according the declaration of Helsinki, and the study protocol was approved by the institutional review board of Children's Hospital, Helsinki University Central Hospital.

The inclusion criteria for the patients were age of 6-15 y, a posttransplant follow-up of minimum of $2 \mathrm{y}$, and no ongoing immunosuppression. The invitation letter was sent to 50 consecutive patients visiting our follow-up clinic and fulfilling the criteria. Eleven patients 
were excluded later: 1 had a secondary malignancy and 10 would have been older than $15 \mathrm{y}$ during the study period. Twenty-five of the 39 eligible patients (64\%) were willing to participate. The patient group comprised 13 males and 12 females, and the median age was $5.2 \mathrm{y}$ (range: $1.1-10.3 \mathrm{y}$ ) at HSCT and $11.0 \mathrm{y}$ (range: 6.4-14.9 y) at the study. Detailed patient characteristics are presented in Table 3. Those who refused to participate did not differ from the study patients with respect to transplant-related demography.

Control subjects were healthy children, 10 boys and 12 girls (median age: $11.9 \mathrm{y}$; range: 6.7-15.5 y). Two control subjects were invited among healthy siblings of children followed up for congenital heart defect from our outpatient Department of Pediatric Cardiology and 20 among age- and gender-matched children of the personnel in Children's Hospital. All control subjects were normotensive, and their echocardiography was normal.

\section{Measurements}

Ultrasound studies and blood pressure measurements. Brachial blood pressure was measured with an oscillometric method (Critikon Dinamap, GE, Waukesha, WI) in the left arm after at least 10 min of rest in the supine position. The pulse pressure was calculated as the difference between systolic and diastolic blood pressure. One experienced investigator (M.I.T.) performed the ultrasound examination of the heart and the carotid and brachial arteries.

We used a real-time B-mode ultrasound imager (Vivid 7; GE Vingmed AS, Horten, Norway) to examine the right CCA. The segment of right CCA $1-2 \mathrm{~cm}$ proximal to the carotid bulb was scanned with a $12 \mathrm{~L}$ vascular probe (GE Medical Systems, Milwaukee, WI), and the resolution box function was used to magnify the arterial far wall. Off-line analysis was performed from the digitally stored data using an automated computerized analyzing system AMS II, v.1.1331 (T. Gustafsson, Gothenburg, Sweden). The IMT and end-diastolic diameter (EDD) were measured from the end-diastolic frames (corresponding to the $\mathrm{R}$ wave). The end-systolic diameter (ESD) was measured from the corresponding systolic maximal diameter during the same cardiac cycles. The mean value of three automatic measurements was used.

Mechanical properties of the CCA. Several parameters are available to characterize the ability of the carotid artery to expand and contract with cardiac pulsation and relaxation. Arterial compliance is defined as an absolute area change for a given pressure step at fixed vessel length. Arterial distensibility is the relative area change for a pressure increment. The $\mathrm{E}$ inc is a pressure step required from resting diameter to theoretical $100 \%$ stretch at fixed vessel wall length and is independent of its geometry.

We used the following formulas:

$\mathrm{CCA}$ compliance $=\pi\left(\mathrm{ESD}^{2}-\mathrm{EDD}^{2}\right) / 4(\mathrm{PP})\left(\mathrm{mm}^{2} \times \mathrm{mm} \mathrm{Hg}^{-1}\right)$ (26)

Pulse pressure $(\mathrm{PP})=\mathrm{P}_{\text {systolic }}-\mathrm{P}_{\text {diastolic }}$

$\mathrm{CCA}$ distensibility $=\left(\mathrm{ESD}^{2}-\mathrm{EDD}^{2}\right) /\left(\mathrm{EDD}^{2} \times \mathrm{PP}\right)\left(\mathrm{mm} \mathrm{Hg}^{-1} 10^{-2}\right)$ (26)

CCA E inc $=[3(1-$ LCSA/WCSA $)] /$ CCA distensibility $(\mathrm{mm} \mathrm{Hg}$ $\left.\times 10^{3}\right)(27)$

Lumen cross-sectional area $($ LCSA $)=\pi\left(\right.$ CCA diameter $\left.{ }^{2}\right) / 4\left(\mathrm{~mm}^{2}\right)$ Wall cross-sectional area $($ WCSA $)=\pi($ CCA diameter $/ 2+$ IMT $) / 2$ $-\pi(\mathrm{CCA} \text { diameter } / 2)^{2}\left(\mathrm{~mm}^{2}\right)(28)$

Flow-mediated dilation. The endothelial-dependent FMD of the brachial artery was measured after at least 30 min of rest with a $12 \mathrm{~L}$ ultrasound probe (Vivid 7, GE, Horten, Norway) as previously described $(14,28)$. The AMS program was used for measuring the changes in the diameter of the brachial artery. The brachial artery was scanned $2-10 \mathrm{~cm}$ above the elbow in a longitudinal section. The center of the artery was identified with the cursor when the clearest images of both posterior and anterior walls were obtained. All the ultrasound scans were stored and automatically analyzed. The mean value was calculated from three cardiac cycles incident with $\mathrm{R}$ wave. The machine settings were chosen to optimize the lumen to vessel wall detection and kept constant during the study. Blood flow in the right arm was restricted distal to the scanned brachial artery by an adult-size blood pressure cuff inflated to $300 \mathrm{~mm} \mathrm{Hg}$ in the forearm for $4 \mathrm{~min}$. After the cuff was deflated, the brachial diameter was scanned for $90 \mathrm{~s}$. The ultrasound scans during $80-90$ s were used for the calculation of the maximal dilation.

\section{Laboratory and Clinical Parameters}

Samples for plasma glucose (glucose oxidation reaction), serum insulin (radioimmunoassay), and plasma lipid measurements were drawn at 8-9 AM after an overnight fast. Insulin resistance was estimated by the homeostasis model assessment from the formula homeostasis model assessment index $=$ fasting glucose $(\mathrm{mmol} / \mathrm{l}) \times$ fasting insulin $(\mathrm{mU} / \mathrm{l}) / 22.5(29,30)$.

Enzymatic assays were used for measuring plasma total cholesterol, cholesterol in high-density lipoprotein cholesterol, and plasma total triglycerides (TG kits; Boeringer Diagnostica, Mannheim, Germany). Low-density lipoprotein cholesterol was calculated according to the Friedewald formula (31).

Along with the anthropometric measurements, chronic GVHD was evaluated according to the modified Seattle approach (32). GVHD was defined as "limited" in case of limited skin involvement with or without signs of hepatic dysfunction. Symptoms and organ manifestations beyond that were considered to be extensive chronic GVHD.

\section{Data Analysis and Statistical Methods}

Arterial diameters were measured by one observer from digitally saved images with an automated system corresponding to at least 100 measurements. Patient characteristics are shown as mean (range). Results are expressed as mean (SD) unless stated otherwise. Comparison between groups was performed by one-way ANOVA. For nonparametric data, the Mann-Whitney $U$ test was used (plasma triglycerides and serum insulin). Univariate linear regression analysis was used to examine the association between continuous variables.

\section{ACKNOWLEDGMENT}

We thank Jani Lehmuskoski for his invaluable help with the figures.

\section{STATEMENT OF FINANCIAL SUPPORT}

This study was supported by grants from Helsinki University Central Hospital Research Funds and the Nona and Kullervo Väre Foundation (Helsinki, Finland). The funders had no role in study design, data collection and analysis, decision to publish, or preparation of the manuscript.

Disclosure: The authors declare no conflict of interest.

\section{REFERENCES}

1. Michel G, Bordigoni P, Simeoni MC, et al. Health status and quality of life in long-term survivors of childhood leukaemia: the impact of haematopoietic stem cell transplantation. Bone Marrow Transplant 2007;40: 897-904.

2. Ness KK, Wall MM, Oakes JM, Robison LL, Gurney JG. Physical performance limitations and participation restrictions among cancer survivors: a population-based study. Ann Epidemiol 2006;16:197-205.

3. Brennan BM, Shalet SM. Endocrine late effects after bone marrow transplant. Br J Haematol 2002;118:58-66.

4. Taskinen M, Saarinen-Pihkala UM, Hovi L, Lipsanen-Nyman M. Impaired glucose tolerance and dyslipidaemia as late effects after bone-marrow transplantation in childhood. Lancet 2000;356:993-7.

5. Tichelli A, Passweg J, Wójcik D, et al.; EBMT Late Effects Working Party. Late cardiovascular events after allogeneic hematopoietic stem cell transplantation: a retrospective multicenter study of the Late Effects Working Party of the European Group for Blood and Marrow Transplantation. Haematologica 2008;93:1203-10.

6. Chatterjee R, Palla K, McGarrigle HH, Mackinnon S, Mckinnon S, Kottaridis PD. Syndrome ' $\mathrm{X}$ ' in adult female recipients of bone marrow transplantation for haematological malignancies. Bone Marrow Transplant 2005;35:209-10.

7. Sorensen KE, Celermajer DS, Georgakopoulos D, Hatcher G, Betteridge DJ, Deanfield JE. Impairment of endothelium-dependent dilation is an 
early event in children with familial hypercholesterolemia and is related to the lipoprotein(a) level. J Clin Invest 1994;93:50-5.

8. Aggoun Y, Bonnet D, Sidi D, et al. Arterial mechanical changes in children with familial hypercholesterolemia. Arterioscler Thromb Vasc Biol 2000;20: 2070-5.

9. Goodfellow J, Bellamy MF, Gorman ST, et al. Endothelial function is impaired in fit young adults of low birth weight. Cardiovasc Res 1998; 40:600-6.

10. Martin H, Hu J, Gennser G, Norman M. Impaired endothelial function and increased carotid stiffness in 9-year-old children with low birthweight. Circulation 2000;102:2739-44.

11. Mäkimattila S, Virkamäki A, Groop PH, et al. Chronic hyperglycemia impairs endothelial function and insulin sensitivity via different mechanisms in insulin-dependent diabetes mellitus. Circulation 1996;94: 1276-82.

12. Järvisalo $M J$, Jartti L, Näntö-Salonen $K$, et al. Increased aortic intimamedia thickness: a marker of preclinical atherosclerosis in high-risk children. Circulation 2001;104:2943-7.

13. Berenson GS, Arbeit ML, Hunter SM, Johnson CC, Nicklas TA. Cardiovascular health promotion for elementary school children. The Heart Smart Program. Ann N Y Acad Sci 1991;623:299-313.

14. Celermajer DS, Sorensen KE, Gooch VM, et al. Non-invasive detection of endothelial dysfunction in children and adults at risk of atherosclerosis. Lancet 1992;340:1111-5.

15. Woywodt A, Haubitz M, Buchholz S, Hertenstein B. Counting the cost: markers of endothelial damage in hematopoietic stem cell transplantation. Bone Marrow Transplant 2004;34:1015-23.

16. Aggoun Y, Szezepanski I, Bonnet D. Noninvasive assessment of arterial stiffness and risk of atherosclerotic events in children. Pediatr Res 2005;58: $173-8$.

17. Woywodt A, Scheer J, Hambach L, et al. Circulating endothelial cells as a marker of endothelial damage in allogeneic hematopoietic stem cell transplantation. Blood 2004;103:3603-5.

18. Biedermann BC. Vascular endothelium and graft-versus-host disease. Best Pract Res Clin Haematol 2008;21:129-38.

19. Woywodt A, Schroeder M, Mengel M, et al. Circulating endothelial cells are a novel marker of cyclosporine-induced endothelial damage. Hypertension 2003;41(3 Pt 2):720-3.
20. Chow AY, Chin C, Dahl G, Rosenthal DN. Anthracyclines cause endothelial injury in pediatric cancer patients: a pilot study. J Clin Oncol 2006;24:925-8.

21. Dengel DR, Ness KK, Glasser SP, Williamson EB, Baker KS, Gurney JG. Endothelial function in young adult survivors of childhood acute lymphoblastic leukemia. J Pediatr Hematol Oncol 2008;30:20-5.

22. Järvisalo MJ, Rönnemaa T, Volanen I, et al. Brachial artery dilatation responses in healthy children and adolescents. Am J Physiol Heart Circ Physiol 2002;282:H87-92.

23. de Groot E, Hovingh GK, Wiegman A, et al. Measurement of arterial wall thickness as a surrogate marker for atherosclerosis. Circulation 2004;10923 Suppl 1:III33-8.

24. Taskinen M, Lipsanen-Nyman M, Tiitinen A, Hovi L, Saarinen-Pihkala UM. Insufficient growth hormone secretion is associated with metabolic syndrome after allogeneic stem cell transplantation in childhood. J Pediatr Hematol Oncol 2007;29:529-34.

25. Reaven GM. Banting lecture 1988. Role of insulin resistance in human disease. Diabetes 1988;37:1595-607.

26. Boutouyrie P, Laurent S, Girerd X, et al. Common carotid artery stiffness and patterns of left ventricular hypertrophy in hypertensive patients. Hypertension 1995;25(4 Pt 1):651-9.

27. Hoeks AP, Brands PJ, Smeets FA, Reneman RS. Assessment of the distensibility of superficial arteries. Ultrasound Med Biol 1990;16:121-8.

28. Aggoun Y, Colomb V, Turanlahti M, et al. Endothelial function and mechanical properties of the common carotid artery in children on parenteral nutrition. Pediatr Res 2004;55:789-93.

29. Matthews DR, Hosker JP, Rudenski AS, Naylor BA, Treacher DF, Turner RC. Homeostasis model assessment: insulin resistance and beta-cell function from fasting plasma glucose and insulin concentrations in man. Diabetologia 1985;28:412-9.

30. Haffner SM, Kennedy E, Gonzalez C, Stern MP, Miettinen H. A prospective analysis of the HOMA model. The Mexico City Diabetes Study. Diabetes Care 1996;19:1138-41.

31. Friedewald WT, Levy RI, Fredrickson DS. Estimation of the concentration of low-density lipoprotein cholesterol in plasma, without use of the preparative ultracentrifuge. Clin Chem 1972;18:499-502.

32. Shulman HM, Sullivan KM, Weiden PL, et al. Chronic graft-versus-host syndrome in man. A long-term clinicopathologic study of 20 Seattle patients. Am J Med 1980;69:204-17. 